\title{
Pengembangan Modul Pembelajaran Tematik Kelas V SD Berbasis Kearifan Lokal untuk Pengenalan Budaya Sedan Rembang
}

\author{
Mufaridah $^{*}$, J.T. Santoso ${ }^{2}$, Achmad Hilal Madjdi $^{3}$ \\ 123 Universitas Muria Kudus, Kudus, Indonesia
}

\begin{abstract}
Abstrak
Tujuan dari penelitian ini adalah untuk menghasilkan modul pembelajaran tematik kelas V SD berbasis kearifan lokal untuk pengenalan budaya Sedan Rembang yang memiliki kevalidan dan keefektifan. Metode penelitian ini mengacu pada teori Borg dan Gall. Langkah penelitian adalah sebagai berikut: penelitian dan pengumpulan informasi, perencanaan penelitian, pengembangan produk awal, uji coba produk awal, revisi hasil uji coba, uji validasi, revisi produk akhir, dan diseminasi. Teknik pengumpulan data yang digunakan adalah wawancara, observasi, dan angket. Analisis yang digunakan dalam penelitian ini adalah analisis kuantitatif dan kualitatif meliputi observasi pembelajaran dan validasi produk bahan ajar. Sumber data pada penelitian ini adalah guru dan siswa kelas V di kecamatan Sedan. Desain pengembangan modul pembelajaran berbasis kearifan lokal ini terdiri atas 3 bagian yaitu pendahuluan, isi, dan penutup. Pada bagian isi modul terdiri atas kutipan kompetensi dasar, tujuan pembelajaran, konsep pembelajaran, serta latihan latihan. Kelayakan produk dilihat dari hasil validasi ahli materi dan ahli bahasa. Dari proses validasi ahli materi diperoleh hasil rata-rata 3,25 dengan persentasi $81 \%$ termasuk kategori sangat baik. Sedangkan validasi ahli bahasa memperoleh hasil rata-rata 3,5 dengan persentasi 83\% dan kategori sangat baik.. Untuk hasil respon guru diperoleh hasil rata-rata 3,73 dengan jumlah skor 470 dengan kategori sangat baik. Untuk hasil respon peserta didik diperoleh hasil rata-rata 3,92 dengan jumlah skor 752 dengan kategori sangat baik. Berdasarkan hasil validasi dan dikuat dengan respon guru dan peserta didik maka modul pembelajaran tematik kelas V SD berbasis kearifan lokal ini dinyatakan layak untuk digunakan dalam proses pembelajaran
\end{abstract}

\begin{abstract}
The purpose of this research is to produce a thematic learning module for class V SD based on local wisdom to introduce the culture of Sedan Rembang which has validity and effectiveness. This research method refers to the theory of Borg and Gall. The research steps are as follows: research and information gathering, research planning, initial product development, initial product testing, revision of trial results, validation testing, final product revision, and implementation. Data collection techniques used were interviews, observation, and questionnaires. The analysis used in this research is quantitative and qualitative analysis including learning observation and validation of teaching material products. Sources of data in this study were teachers and fifth grade students in Sedan sub-district. Product feasibility is seen from the validation results of material experts and linguists. From the material expert validation process, it was obtained an average result of 3.25 with a percentage of $81 \%$ including the very good category. Meanwhile, the linguist validation obtained an average result of 3.5 with a percentage of $83 \%$ and the category was very good. Based on the results of the validation, the thematic learning module for class V SD based on local wisdom was declared feasible to be used in the learning process.

Keywords:

Modul of Thematic Learning, Local Wisdom, Introduction of Culture
\end{abstract}

\footnotetext{
* Corresponding author. 


\section{PENDAHULUAN}

Pendidikan merupakan kebutuhan yang sangat penting dalam meningkatkan kualitas sumber daya manusia. Salah satu komponen dari sistem pendidikan adalah kurikulum. Pembelajaran pada kurikulum 2013 menggunakan model tematik terpadu, pendekatan saintifik, dan penilaian autentik.

Pendekatan Saintifik sebagaimana dimaksud Permendikbud Nomor 103 Tahun 2014 meliputi lima pengalaman belajar, yaitu mengamati, menanya, mencoba, menalar, dan mengkomunikasikan. Dalam implementasi Kurikulum 2013, peserta didik tidak mempelajari tiap mata pelajaran secara terpisah, melainkan secara tematik terpadu. Pembelajaran tematik terpadu adalah sistem pembelajaran yang mengintegrasikan komponen dari berbagai mata pelajaran yang dipadukan dalam satu tema. Tema yang dipilih adalah berkenaan dengan alam dan kehidupan manusia. Keberhasilan dalam pembelajaran sangat tergantung pada kemampuan pendidik dalam merencanakan dan menentukan tujuan belajar peserta didik melalui penggunaan bahan ajar.

Pembelajaran tematik adalah pembelajaran terpadu yang mengggunakan tema untuk mengaitkan beberapa mata pelajaran sehingga dapat memberikan pengalaman bermakna kepada siswa. Pembelajaran tematik juga dapat diartikan sebagai program pembelajaran yang berangkat dari satu tema/topic tertentu dan kemudian dielaborasi dari berbagai aspek atau ditinjau dari berbagai perspektif mata pelajaran yang biasa diajarkan di sekolah (Abdul Khadir, 2015:1) Pembelajaran tematik merupakan pembelajaran yang diterapkan dalam kurikulum 2013 (Sari \& Syamsi, 2015). Pembelajaran tematik adalah pembelajaran yang dirancang berdasarkan tema-tema tertentu yang dalam pembahasannya tema itu ditinjau dari berbagai mata pelajaran (Majid, 2014). Menurut Parmin (2012) Modul merupakan komponen yang penting dalam proses perkuliahan. Ketersediaan modul dapat membantu mahasiswa dalam memperoleh informasi tentang materi pembelajaran yang kontekstual karena modul disusun oleh dosen yang mengajar. Modul Pembelajaran Tematik merupakan komponen penting dalam pembelajaran. Modul Pembelajaran Tematik diperlukan sebagai pedoman beraktivitas dalam proses pembelajaran. Pembelajaran tematik mengarahkan guru agar lebih kreatif dan inovatif sehingga dapat menghasilkan pembelajaran yang utuh (Estuwardani \& Mustadi, 2015). Pengembangan tema pada pembelajaran tematik Kurikulum 2013 bertujuan agar proses pendidikan dapat menghasilkan insan Indonesia yang produktif, kreatif, inovatif, dan afektif melalui penguatan sikap dan pengetahuan yang terintegrasi. Berdasarkan Permendiknas Nomor 16 Tahun 2007, Guru diharapkan mampu mengembangkan bahan ajar dengan memerhatikan karakteristik dan lingkungan sosial peserta didik. Pendidikan yang relevan harus menghargai dan mengembangkan keutamaan lokal, nilai-nilai yang didapat dalam suatu masyarakat dapat menjadi panduan dalam mendesain pendidikan karakter. Kearifan lokal begitu melekat dengan ciri khas yang ada pada suatu daerah. Potensi yang dimiliki suatu daerah yang dapat dimanfaatkan dan diolah menjadi suatu barang atau jasa yang sangat bernilai untuk menambah penghasilan daerah yang memiliki keunikan serta memiliki keunggulan yang dapat bersaing dengan daerah lain disebut sebagai kearifan lokal. Menurut Mumpuni (2013), kearifan lokal atau yang sering disebut dengan budaya lokal, merupakan budaya asli yang berasal dan berkembang pada masyarakat di suatu daerah, sehingga kearifan lokal ini menggambarkan ciri khas dari suatu daerah tertentu. Kearifan lokal daerah, perlu untuk sedini mungkin dikenalkan kepada peserta didik. Hidayat (2013), adanya ketidaktahuan peserta didik terhadap kearifan lokal budaya daerah sendiri, mengakibatkan tujuan pendidikan tidak tersampaikan dengan baik, sehingga mengakibatkan tidak adanya pelestarian serta eksistensi dari generasi penerus terhadap kearifan lokal untuk di pelajari dan dimasukkan dalam proses pendidikan ataupun dalam praktik di kehidupan seharihari. Menurut Chusna (2019) untuk mengenalkan kearifan lokal ini guru perlu memasukkan materi yang menggunakan kearifan lokal dalam proses pembelajaran, supaya peserta didik dapat mempertahankan pengetahuan daerah dalam menghadapi perkembangan serta kemajuan pendidikan terhadap ciri khas budaya yang dimiliki daerah disekitarnya. Menurut Ekowati (2017), budaya lokal berfungsi sebagai sarana dalam menyampaikan pembelajaran dengan lebih menekankan kepada tercapainya sebuah pemahaman yang terpadu daripada pemahaman mendalam.

Berdasarkan hasil observasi yang dilakukan di kelas V SDN 2 Dadapan Kecamatan Sedan pada tanggal 29 Juli 2019, diketahui bahwa dalam pembelajaran peserta didik kurang didorong untuk mengetahui dan mengembangkan potensi yang ada di alam sekitar tempat tinggalnya. Mereka hanya memahami konsep-konsep dengan cara menghafal materi yang ada di buku ajar. Penyampaian materi masih terpaku pada buku ajar. Untuk itu, pendidik mengembangkan bahan ajar yang sesuai dengan kondisi yang ditemui di lapangan serta mampu mengangkat kearifan lokal sehingga peserta didik dapat mengenal dan memahami kearifan lokal yang ada di Kabupaten Rembang, khususnya lingkungan sekitar tempat tinggal peserta didik. 


\section{METODE PENELITIAN}

Dalam penelitian ini digunakan desain penelitian dan pengembangan dengan sepuluh langkah pelaksanaan mengacu pada teori Borg dan Gall. 10 langkah dalam penelitian tersebut yakni (1) penelitian dan pengumpulan informasi, (2) perencanaan penelitian, (3) pengembangan produk awal, (4) uji coba awal, (5) revisi produk berupa modul pembelajaran, (6) uji coba kelompok kecil, (7) revisi hasil uji (8) uji validasi (9) revisi produk ahli (10) diseminasi.

Validasi produk oleh ahli bahasa pada 22 Agustus 2020 dan ahli materi pada 26 Agustus 2020. Instrumen pengumpulan data pada penelitian ini adalah pedoman wawancara, pedoman observasi, dan angket.

Adapun teknik pengumpulan data yang dilakukan peneliti adalah menggunaka, wawancara, obsrevasi, dan angket.

Analisis validasi tersebut menggunakan skala tipe ratting scale dengan langkah-langkah sebagai berikut. a) Validator memberikan skor pada item pernyataan. Skor jawaban tersebut meliputi kategori sebagai berikut : (4) sangat baik, (3) baik, (2) cukup, (1) kurang; b) Skor total tiap validator dijumlahkan pada semua indikator; c) Mencari hasil nilai validitas menggunakan rumus :

$$
p p=\frac{\sum f x 100 \%}{n}
$$

Keterangan :

$$
\begin{aligned}
& \mathrm{P}: \text { Nilai Akhir } \\
& \mathrm{F}: \text { Perolehan Skor } \\
& \mathrm{n}
\end{aligned}
$$

Hasil yang diperoleh diintepretasikan dengan kriteria sebagai berikut.

Tabel 1. Kriteria Validitas Perangkat Penilaian

\begin{tabular}{ccc}
\hline No & Nilai & Kategori \\
\hline 1 & $81-100 \%$ & Sangat baik \\
2 & $61-80 \%$ & Baik \\
3 & $41-60 \%$ & Cukup \\
4 & $21-40 \%$ & Kurang \\
5 & $<21 \%$ & Kurang sekali \\
\hline
\end{tabular}

Sebuah media yang dikembangkan akan dikatakan layak untuk digunakan sebagai media dalam pembelajaran apabila persentasenya yang diperoleh dari proses validasi lebih dari $61 \%$.

\section{ANALISIS DAN PEMBAHASAN}

Validasi ahli dilakukan untuk memberikan penilaian kevalidan terhadap modul pembelajaran tematik dilihat dari segi aspek fisik dan penyajian serta untuk memperoleh kritik dan saran dari validator serta untuk proses revisi produk bahan ajar. Validator media yakni Kanzunnudin dan Bahrudin, selaku dosen Program Pendidikan Bahasa Universitas Muria Kudus dan guru sekolah dasar. Validasi mediadilakukan pada 22 Agustus 2020 dan 26 Agustus 2020.

Validasi ahli untuk aspek kelayakan isi materi terdiri atas kesesuaian materi dengan KD, keakuratan materi, kemutakhiran materi, dan penilaian karakter. Dari aspek kelayakan bahasa terdapat 4 indikator penilaian yaitu lugas, komunikatif, interaktif, kesesuaian dengan perkembangan peserta didik. Secara keseluruhan angket validasi ahli dari aspek materi dan bahasa terdapat 22 item pernyataan. Skor dari setiap aspek penialain angket adalah 4 dengan kategori (sangat baik), 3 dengan kategori (baik), 2 dengan kategori (cukup), 1 dengan kategori (kurang). Adapun hasil validasi dari aspek materi dan bahasa dapat dilihat dalam table sebagai berikut. 
Tabel 2. Valisadi Materi

\begin{tabular}{|c|c|c|c|}
\hline No. & Indikator Penilaian & Butir Penilain & Skor \\
\hline 1 & Kesesuaian materi dengan KI dan KD & 4 item & 15 \\
\hline 2 & Keakuratan Materi & 7 item & 25 \\
\hline 3 & Kemutakhiran Materi & 4 item & 14 \\
\hline 4 & Penilaian Karakter & 1 item & 3 \\
\hline \multicolumn{2}{|r|}{ Jumlah } & 16 item & 57 \\
\hline \multicolumn{2}{|r|}{ Rata-Rata } & & 3,56 \\
\hline \multicolumn{2}{|r|}{ Persentase } & & $89 \%$ \\
\hline \multicolumn{2}{|r|}{ Kategori } & \multicolumn{2}{|c|}{ Sangat Baik } \\
\hline
\end{tabular}

Tabel 3. Validasi Bahasa

\begin{tabular}{|c|c|c|c|}
\hline No & Indikator Penilaian & Butir Penilain & Skor \\
\hline 1 & Lugas & 2 item & 8 \\
\hline \multirow{2}{*}{$\begin{array}{l}2 \\
3\end{array}$} & Komunikatif & 2 item & 7 \\
\hline & $\begin{array}{l}\text { Kesesuaian dengan perkembangan peserta } \\
\text { didik }\end{array}$ & 2 item & 7 \\
\hline & Jumlah & 6 item & 22 \\
\hline & Rata-Rata & & 3,67 \\
\hline & Persentase & & $92 \%$ \\
\hline & Kategori & & \\
\hline
\end{tabular}

Dari aspek kelayakan materi modul pembelajaran tematik berbasis kearifan lokal untuk pengenalan budaya Sedan Rembang pada siswa kelas 5 Sekolah Dasar memperoleh jumlah skor 57 ratarata 3,56 dengan persentase $89 \%$ dengan kategori sangat baik,aspek bahasa dalam modul pembelajaran tematik berbasis kearifan lokal untuk pengenalan budaya Sedan Rembang pada siswa kelas 5 Sekolah Dasar memperoleh jumlah skor 22 rata-rata 3,67 dengan persentase 92\% dengan kategori sangat baik.

Hasil validasi dari aspek produk media berupa modul pembelajaran tematik ada 2 indikator penilaian dengan 5 item pernyataan. Ada 3 item yang memperoleh skor 4 dengan kategori sangat baik, dan 2 item pernyataan mendapat skor 3 dengan kategori baik. Hal ini menunjukkan bahwa produk media berupa modul pembelajaran tematik yang digunakan dalam pembelajaran tematik menarik, jelas, dan tepat sasaran.

Dalam proses validasi peneliti mendapat beberapa saran. Saran dari ahli digunakan untuk melakukan proses revisi produk sehingga revisi produk tidak dilakukan secara menyeluruh melainkan hanya sesuai dengan saran validator saja. Adapun saran validator sebagai berikut: a) Mengubah kata pengantar menjadi prakata, b) Mengubah isi modul dari satu subtema menjadi satu tema, c) Mengganti desain cover dari subtema 2 menjadi satu tema.

Setelah diperoleh hasil validasi, maka peneliti akan menggunakan modul pembelajaran tematik dalam pembelajaran. Keefektifan modul ini dengan menggunakan angket melalui google formulir. Angket diberikan untuk guru di wilayah daerah kecamatan Sedan dengan mengisi pernyataan yang terdapat pada angket.

Secara keseluruhan dari dapat ditarik kesimpulan bahwa modul pembeajaran tematik berbasis kearifan lokal Sekolah Dasar ini layak digunakan dalam pelaksanaan pembelajaran tema 1 kelas 5 SD. Hal ini sejalan dengan hasil penelitian yang dilakukan oleh Zinnurain dan Ahmad Muzanni tahun (2016) dalam judul pengembangan bahan ajar berbasis kearifan lokal kelas V Sekolah Dasar menyimpulkan bahwa bahan ajar yang dikembangkan berdasarkan kearifan lokal yang ada di daerah masing-masing dapat meningkatkan hasil belajar siswa. Hal ini senada dengan hasil penelitian yang dilakukan oleh Yusintus dkk dalam penelitiannya tahun (2017) dengan judul Pengembangan bahan ajar tematik berbasis kearifan lokal sebagai upaya melestarikan nilai budaya pada siswa sekolah dasar.

\section{KESIMPULAN}

Berdasarkan hasil validasi dan wawancara maka modul pembelajaran tematik berbasis kearifan lokal untuk pengenalan budaya sedan rembang siswa kelas 5 sekolah dasar dinyatakan layak untuk digunakan dalam proses pembelajaran. Dengan adanya modul pembelajaran tematik pada siswa kelas 5 sekolah dasar berbasis kearifan lokal untuk pengenalan budaya Sedan Rembang diharapkan dapat 
menambah ilmu pengetahuan tentang keanekaragaman budaya yang ada di tempat tinggal khususnya di daerah Sedan Rembang

\section{DAFTAR PUSTAKA}

Adi, Bayu laksono. 2018. An Investigation of Local Wisdom To Support Adult Literacy Program. https://grdspublishing.org/index.php/people/article/view/1559. Diunduh pada 30 Januari 2019.

Chusna, Ludvi Novisatul, Dyah Worowirastri Ekowati, Kuncahyono. 2019. Modul Pendamping Pembelajaran Tematik Berbasis Kearifan Lokal Blitar di Kelas IV SD. - Indonesian Journal of Primary Education - Vol .3, No. 1, Hal, 81-92. Tersedia Pada: http://ejournal.upi.edu/index.php/IJPE/index.

Dek Ngurah. 2016. Pengembangan Bahan Ajar Tematik Sd Kelas IV Berbasis Kearifan Lokal Masyarakat Ngada. http://ejournal.citrabakti.ac.id/index.php/jipcb/article/view/74. Diunduh pada 28 Januari 2020.

Ekowati, D. W., Kusumaningtyas, D. I, \& Sulistyani, N. 2017. Ethnomathematica. dalam Pembelajaran Matematika (Pembelajaran Bilangan dengan Media Batik Madura, Tari Khas Trenggal dan Tari Khas Madura. Jurnal Pemikiran dan Pengembangan SD. 5 (2): 716-722.

Estuwardani, N. A., \& Mustadi, A. (2015). Pengembangan Bahan Ajar Modul Tematik-Terintegratif dalam Peningkatan Karakter Peserta Didik Kelas 1 Sekolah Dasar. Jurnal Pendidikan Karakter, 5(2), 157-172. Retrieved from https://journal.uny.ac.id/index.php/jp ka/article/view/8620/7113

Hidayat, Sholeh. 2013. Pengembangan Kurikulum Baru (A.S. Wardan, Ed). Bandung: PT Rosdakarya.

Kadir, Abd. 2015. Pembelajaran Tematik. Jakarta: RajaGrafindo Persada.

Majid, A. (2014). Pembelajaran Tematik Terpadu. Bandung: PT. Remaja Rosdakarya

Mohammad Kanzunnudin. 2012. The Important Role of Fairy Tale in Investing National's Culture Values. Eprints.umk.ac.id. diunduh pada 20 Januari 2020

Mohammad Kanzunnudin, dkk. 2019. Education In Era 4.0 Based On Local Wisdom:Existence Of Value And Technology.

https://www.researchgate.net/publication/336514678_Education_In_Era_40_Based_On_Local_W isdom_Existence_Of_Value_And_Technology. Diunduh pada 27 Januari 2020

Mohammad Kanzunnudin, dkk .2017. Structure and Values of Story Pross of the People of Kudus Society. available at http: www.serialsjournal.com.

Mumpuni, K. E. 2013. Potensi Pendidikan Keunggulan Lokal Berbasis Karakter dalam Pembelajaran Biologi di Indonesia. Makalah disajikan pada Prosiding Seminar Nasional X Pendidikan Biologi FIP UNS. (Online), (http://jurnal.fkip.uns.ac.id/index.php/pr osbio/article/),

Nurul Zuriah. 2016. Ibm Guru Dalam Pengembangan Bahan Ajar Kreatif Inovatif Berbasis Potensi Lokal. http://ejournal.umm.ac.id/index.php/dedikasi/article/view/3136.

Parmin. 2012. Pengembangan Modul Pembelajaran IPA Terpadu Berwawasan Sains, Lingkungan, Teknologi dan Masyarakat. Jurnal Penelitian Pendidikan Vol. 29 Nomor 2 Hal. 125-136. Tersedia pada: https://journal.unnes.ac.id/nju/index.php/JPP/article/view/5654.

Permendikbud Nomor 67 Tahun 2013 Tentang Kerangka Dasar dan Struktur Kurikulum Sekolah Dasar/Madrasah Ibtidaiyah. 
Sari, I. P., \& Syamsi, K. (2015). Pengembangan Buku Pelajaran Tematik-Integratif Berbasis Nilai Karakter Disiplin dan Tanggung Jawab Di Sekolah Dasar. Jurnal Prima Edukasia, 3(1), 73-83. https://doi.org/10.21831/JPE.V3I1.4 070.

Selfi Melindawati. 2016. Pengembangan Bahan Ajar Tematik Terpadu Dengan Model Problem Based Learning Di Kelas IV Sekolah https://pdfs.semanticscholar.org/d8af/8f0048599a68c831c96b5616389e5f23b99e.pdf. Diunduh pada 1 Februari 2020

Yuliana, Siti Sriyati, Yayan Sanjaya. 2017. Local wisdom of Ngata Toro community in utilizing forest

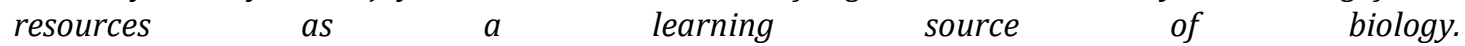
https://www.researchgate.net/publication/318923143_Local_wisdom_of_Ngata_Toro_communit y_in_utilizing_forest_resources_as_a_learning_source_of_biology. Diunduh pada 26 Januari 2020 